\title{
Mycotoxins in Children's Food: Problem and Halal Management
}

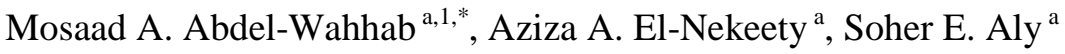 \\ ${ }^{a}$ Food Toxicology \& Contaminants Department, National Research Center, Dokki, Cairo, Egypt \\ 1mosaad abdelwahhab@yahoo.com_(MAA), Tel.: +2 2283 1943; fax: +2 3337 0931) \\ * corresponding author
}

ARTICLE INFO

\section{Article history}

Received June 05, 2019

Revised August 31, 2019

Accepted November 02, 2019

Keywords:

mycotoxins

food

children

infants

diseases

halal strategies

\section{ABSTRACT}

Mycotoxins are ubiquitous compounds found in the natural life cycle of food- producing plants. They have a range of diverse chemical and physical properties and toxicological effects on man and animal. Mycotoxins are considered the most important contaminants of the food chain due to their chronic adverse effects on health and the economy. Mycotoxins are known as the $21^{\text {th }}$ century "Great Masquerader" due to its complex natural history involving different tissues and resembling different diseases at each stage in its evolution. Mycotoxins can induce a variety of clinical symptoms including epistaxis, conjunctivitis, coughing, apnea, wheezing, vomiting and nausea. Some mycotoxins induce acute pulmonary hemorrhage, bone marrow failure and pneumonia. Knowledge about these symptoms enables the clinician to ask questions for possible exposure to the main classes of mycotoxins to protect children from sources of such exposure. These sources may include food, clothes, furniture and indoor air at home. Early childhood exposure to mycotoxins may be critical determinants of later health effects. Exposure in utero and through early infancy may additionally be important. Several well-known diseases such as neural tube defects, liver and esophageal cancers are associated with the consumption of mycotoxin-contaminated food. Knowledge of previous short or long term exposure to mycotoxins may help paediatricians to more accurately diagnose and provide treatment options to children and their families. The current review discusses the problems associated with the occurrence of different common mycotoxins in children's food and the possible halal strategies to counteract these problems.

This is an open access article under the CC-BY-SA license.

\section{Introduction}

Recently, there has been much interest in paediatricians to understand the link between exposure to fungi and health problems in children and infants. The most at- risk and important target group in this focus are children who suffer from immune deficiency and those living in developing countries in Asia and Africa. Several studies on immunodeficiency disease in children in industrialized countries including the USA have identified allergic symptoms from exposure to fungi and/or their toxic metabolites. Primary care paediatricians are unaware of the toxic properties of fungi and many find themselves confused and somewhat puzzled by the often contradictory information in the literature. 
Mycotoxins comprise a structurally diverse family of naturally occurring, fungal-elaborated toxins, many of which have been strongly implicated as chemical precursors for toxicity in humans and animals (Pereira et al. 2014; Sun et al. 2017). The significance of mycotoxin- induced health effects derives from the natural occurrence of mycotoxins as contaminants of crops and food, and the possibility of exposure across all ages. Consumption of foods heavily contaminated with mycotoxins has resulted in acute intoxication episodes in many human populations. Chronic health conditions from exposure to minute amounts of mycotoxins are varied and principally include cancer. Human exposure to mycotoxins is difficult to avoid because fungal growth in foods is difficult to prevent (CAST, 2003).

From a system perspective, mycotoxins can be addressed in three interacting subsystems: metabolism and toxicology; health and productivity; and wealth. These subsystems significantly interact. After exposure to mycotoxins by inhalation, ingestion or skin contact, metabolism of the mycotoxins leads to several sequential events that determine toxicity. These events include administration, absorption, transformation, pharmacokinetics, molecular interaction, distribution, and excretion of these toxins and their metabolites. Thus, mycotoxin toxicity affects human and animal health, which affects the production of wealth related to human endeavour, agriculture and livestock production (FAO, 2001). The Food and Agriculture Organization (FAO) of the United Nations estimated in 1996 that $25 \%$ of the world's grain supply would be contaminated with mycotoxins (FAO, 1996). However, the exact economic cost of mycotoxins on crops and livestock is impossible to accurately determine because of the lack of sufficient data (CAST, 2003).

Exposure to mycotoxins is mostly via ingestion, however; other routes such as inhalation, contact and passive exposure resulting from mycotic infection by toxigenic fungi, have been recognized (CAST, 2003). Humans can be exposed to mycotoxins directly via consumption of contaminated commodities or indirectly via the consumption of animal products (milk, meat, eggs) derived from animals that have consumed contaminated feeds. A widely studied example is the carry-over of aflatoxins from feed into milk and milk products, where they appear mainly as aflatoxin $\mathrm{M}_{1}$ or other secondary contaminated animal products (FAO, 2001; Marin et al., 2013). Mycotoxins also are relatively stable to heat; therefore, food preparation processes and procedures using heat such as cooking cannot be expected to remove mycotoxins safely (Bullerman, 2002; Hisako et al., 2013; Kaushik, 2015).

Animal studies, observational and epidemiological evidence indicate involvement of fungal metabolites in human disease as toxic or carcinogenic etiological agents (IRAC, 1993a,b,c,d,e; Marin et al., 2013). Human disease caused by mycotoxins may be a larger public health problem than anticipated because a long period is elapsed before the illness is recognized unless large amounts of mycotoxins are consumed, resulting in acute symptomology (Alshannaq and $\mathrm{Yu}$, 2017). With advances in research, the significance of mycotoxins to human health is increasingly being recognized (CAST, 2003; Fung and Clark, 2004; Williams et al, 2004). Still, as with pesticides, lifelong consequences of exposure to chemicals in early life are just beginning to be observed (Forrest and Riley 2004; NAS, 2004).

The impact of hazardous mycotoxin exposure on human health can take numerous shapes, levels of severity and clinical significance. Generally, the degree of toxicity of different chemicals tested on laboratory animals is affected by differences in species, age (foetus, young or old), and sex. In humans, mycotoxins can cause important health problems evidenced by occasional outbreaks of acute human mycotoxicoses (CDCP, 2004; Zain, 2011). Carcinogenicity is the most recognized late-onset disease from exposure to mycotoxins in humans. In exposed populations in Asia and West Africa, hepatitis B virus infection (and also hepatitis C virus infection) may confound the relationship between aflatoxin ingestion and liver cancer (Wogan, 1999; Magnuson et al., 2013). There have been some cases of infant death linked to presence of mold in living conditions (CDCP, 2000; Jarvis, 2002).

Among the many responses attributed to mycotoxin exposure is disturbed growth development in children, several types of cancer, reduced fertility and stillbirths (Barrett, 2000; Gong et al., 2016). Immuno-modulation caused by chronic exposure to mycotoxins is likely an important aspect of 
their adverse health effects. In animal studies, consumption of sufficient amounts of mycotoxins leads to immuno-suppression involving specific classes of immunoglobulins or antibodies. However, the major effects appear to involve cellular immune phenomena and non-specific humoral factors associated with immunity. Immune-suppression is a likely major health effect of mycotoxins (CAST, 2003).

Mycotoxins affect diverse cellular processes and have a wide spectrum of toxicological effects. This complexity is reflected in the diversity of responses in different animal species. This is likely to translate into differences in human response depending on race and even in individuals of the same race. These toxins may affect the reproductive system, immune system, hormonal activity, target organs and the nervous system. Developmental defects including birth defects are another possible adverse effect following exposure to mycotoxins. In addition to these diverse organ or site-specific actions, mycotoxins may affect the gastrointestinal system, have haematological effects and reduce growth (Weidenborner, 2001; Kuiper-Goodman, 2004).

Worldwide, large numbers of vulnerable children are exposed to food contaminated with mycotoxins. In communities exposed to mycotoxins, the hazardous impact of mycotoxins can affect pregnancy, lactation and child growth (Williams et al, 2004; Smith et al., 2017). Children are a nutritionally vulnerable group and they are behaviorally (naughty, defiant and impulsive from time to time, oppositional defiant disorder, conduct disorder and attention deficit hyperactivity disorder) and physiologically different from adults. Their susceptibility to the adverse health effects of mycotoxins is also likely different from adults (WHO; 1986, 2006). The disproportionate impact of exposure to toxic substances on children compared to adults has led to much- deserved research efforts. Exposure to chemical agents such as pesticides at the child developmental stage produces effects that differ qualitatively and quantitatively from those in adult exposure, and represents a major empirical and conceptual foundation for child health risk assessment (NAS, 1993). Because their organ systems are growing and developing, they may be more susceptible to toxins and respond differently to environmental challenges at various stages of development. The manifestations of developmental toxicity will vary depending on the time of exposure and the underlying developmental processes at that growth stage (Scheuplein et al, 2002; Tamburlini et al. 2002; Thompson, 2004).

The risks associated with mycotoxin exposure in children depend on the degree of exposure and the degree of toxicity of the mycotoxin. It has been found, consistently, that naturally contaminated grains are more toxic than known pure mycotoxins. This is due presumably to the presence of and interaction with other identified or as yet unidentified mycotoxins or metabolites. These additional substances need to be considered in the overall exposure assessment for children, and in hazard and risk assessments for children (Kuiper-Goodman, 1991). Infants and children are more susceptible to different toxins compared to adults because of their lower body weight, higher metabolic rate, lower detox capabilities, and on-going development of essential organs and tissues, such as in the central nervous system.

The Acceptable Daily Intake of any chemical (ADI) is defined as the amount of chemicals that can be ingested daily over a lifetime without appreciable health risk. However, there has been ongoing debate on the question of whether the limits afford protection to all sectors of the human population (Bellisle and Rolland-Cachera, 2000). Focus has been particularly centred on whether infants (from birth to 12 months) and children (1 to 12 years of age) are adequately protected by the ADI, because of hypothetical concerns that:

- Infants and children may differ in their capacity to detoxify and eliminate chemicals from the body (toxicokinetics).

- Infants and children may be more sensitive to toxicity (toxicodynamics)

In addition, different dietary requirements and habits may result in intake of chemicals exceeding the ADI. Although derivation from the ADI allows for assessment of possible effects on neonatal animals, the values are considered inappropriate to apply in infants below the age of 12 weeks. 
There are two reasons for this: (1) Insufficient data is available with respect to the effects of chemicals on very young infants. It is known that enzyme levels responsible for biotransformation are generally much lower in the newborn, particularly in the pre-term infant. Lower levels of enzyme activity can potentially lead to impaired detoxification or to decreased formation of toxin metabolites. There are also some types of toxic effects to which the neonate is more sensitive, as a result of its rapidly changing physiology. These factors increase the uncertainty in establishing safe intake levels for the infant in the first few weeks of life. (2) Exposure to suckling animals via the mother's milk mimics the situation of the breast-fed infant, but routine studies do not simulate direct exposure to additives in infant milk formula (Benford, 2001).

The available scientific data supports suggestions that older infants and children are at greater risk from toxin than adults. As already noted, a large number of biochemical and physiological changes occur in the early stages of life. These may influence the rates of absorption, distribution, metabolism and excretion from the body (Worm et al., 2000). In particular, the various enzymes involved in metabolism of toxic compounds develop at different rates in the first few weeks after birth. However, although large differences are present in enzyme levels and physiological functions between infants and adults, these differences do not seem to have major implications for the fate of the toxic compounds ingested into the body. Studies on a wide range of drugs have shown that the rate of elimination in infants was similar to, or in some cases higher than that in adults (Sohn, et al., 2000). This means that variation between infants and adults is covered under the "toxicokinetic safety factor".

\section{Mycotoxins}

\subsection{Mycotoxins in breast milk}

\subsubsection{Aflatoxins}

Aflatoxins are highly toxic secondary fungal metabolites produced by Aspergillus flavus and A. parasiticus. When lactating women ingest an aflatoxin-contaminated diet, a major aflatoxin metabolite, aflatoxin $\mathrm{M}_{1}\left(\mathrm{AFM}_{1}\right)$ is secreted into the milk (Polychronaki et al., 2006; Prandini et al., 2009). $\mathrm{AFM}_{1}$ has been reported as carcinogenic (Luongo et al., 2014) and mutagenic (IARC, 2015). Young infants are more sensitive to $\mathrm{AFM}_{1}$ compared to adults. The symptoms are identical to that of Reye's syndrome and Kwashiorkor, both of which have been conjecturally associated with aflatoxins (Shank, 1997; WHO, 1999).

\subsubsection{Ochratoxin (OA)}

Humans are exposed to OA via consumption of foods directly contaminated with fungus growth and food by-products derived from exposed animals. OA is reported as nephrotoxic, carcinogenic, teratogenic and immunosuppressive (Abdel-Wahhab et al., 2005, Ringot and Chango, 2010, Heussner and Bingle 2015). In human milk samples, the highest concentrations of OA have been found in Sierra Leone (Table 1), where 35\% of the samples contained OA at levels from 200 to 337 $\mathrm{ng} / \mathrm{ml}$ (Miraglia et al., 1995; Jonsyn et al., 1999). OA in breast-milk was reported to affect kidney function and led to the development of urinary tumours in infants and young children (Skaug et al., 1998).

\subsection{Mycotoxins in bottle-fed infants:}

Contaminated water supply, poor bottle cleaning procedures, poor storage facilities, and having only one bottle, teat and funnel for the preparation of bottled milk make the preparation of uncontaminated, bacteriologically safe milk extremely difficult, if not impossible, in real-life circumstances faced in tropical homes. This was true even when attempted by trained health staff for trial purposes (Gursky, 2000). Johnston and Monte (2000) summarized the situation as follows: Bottle-fed infants are particularly prone to diarrheal diseases, which are almost unavoidable under the poor hygiene conditions of households of modest income. A vicious circle sets in diarrheal disease, reduced intake (due to semi-starvation or starvation diet), early malnutrition, reduced 
appetite, reduced resistance, and further diarrhoea (Baskaran et al., 1999). Cow's milk-based infant formulas may be contaminated by different contaminant residues i.e. mycotoxins (Skaug, 1999), especially $\mathrm{AFM}_{1}$ (Galal-Gorchev, 1993; Oliveira, et al., 1997). These contaminant residues induce health hazards in small children who consume large quantities of milk.

\subsection{Mycotoxins in children's food:}

As mentioned above, mycotoxins comprise a structurally diverse family of naturally occurring, fungal-elaborated toxins, many of which have been strongly implicated as chemical precursors of toxicity in humans and animals. Exposure to mycotoxins is difficult to avoid because fungal growth in foods is not easy to prevent (Bellisle and Rolland, 2000). Consumption of foods heavily contaminated with mycotoxins has resulted in acute intoxication episodes in children. Table (1) summarizes selected mycotoxin-producing fungi of relevance to children's health.

Table 1. Selected mycotoxin-producing fungi of relevance to children's health.

\begin{tabular}{lll}
\hline Fungus & Mycotoxins & Associated health effects \\
\hline Aspergillus flavus, A. Parasiticus & Aflatoxins & Vomiting, hepatitis, Liver cancer \\
Fusarium verticillioides & Fumonisins & Vomiting, Neural tube defects, Esophageal cancer \\
Fusarium culmorum & Deoxynivalenol & Vomiting \\
Fusarium sporotrichiodes & T-2 toxin & Alimentary toxic aleukia, Vomiting, hemorrhage \\
Aspergillus ochraceus, A. niger & Ochratoxins & Balkan nephropathy, Renal cancer \\
Penicillium expansum & Patulin & Vomiting, cancer (suspect) \\
Fusarium graminearum & Zearalenone & Estrogenic effects, cervical cancer (suspect) \\
Claviceps purpurea & Ergot alkaloids & Ergotism \\
\hline
\end{tabular}

Generally, the degree of toxicity of different chemical compounds on laboratory animals is found to be affected by differences in species, age, and sex. In humans, children are considered to be more susceptible than adults. The mycotoxins that are highly toxic to children are described as the following:

\subsubsection{Aflatoxin}

Aflatoxin refers to a group of potent toxins that are found in a wide range of agricultural crops especially grains and nuts which are commonly used for the preparation of children's food (Kensler et al., 2011; Bhatnagar-Mathur et al., 2015; Verheecke et al., 2016). Up to now, several aflatoxins have been discovered and the most important, naturally-occurring are $B_{1}, B_{2}, G_{1}$, and $G_{2}$. Aflatoxins have continued to receive attention as the most carcinogenic and toxic mycotoxin (IRAC, 1993a, CAST, 2003; Ostry et al. 2017; El-Nekeety et al., 2017) with mutagenic and teratogenic properties when tested in laboratory animals (Abdel-Wahhab et al., 2010, 2015, 2016; Milićević et al. 2016; Kumar 2017). For this reason, they may be hazardous to humans and especially children and infants. In many species, the major target for acute and chronic toxicity due to aflatoxin exposure is the liver.

The human gastrointestinal tract rapidly absorbs aflatoxins after consumption of contaminated food, and the circulatory system transports the aflatoxins to the liver (Fung and Clark, 2004). 1 to $3 \%$ of ingested aflatoxins irreversibly bind to proteins and DNA bases to form adducts such as aflatoxin $B_{1}$-lysine in albumin (Skipper and Tannenbaum, 1990). Because aflatoxin $B_{1}$-lysine adducts are not repaired, their half-life in human serum is approximately 20-60 days (AzzizBaumgartner et al., 2005). In 1993, the International Agency for Research on Cancer determined 
that aflatoxin $\mathrm{B}_{1}$ (the most potent of the aflatoxins) was a human carcinogen (IARC, 1993a; Ostry et al. 2017). Epidemiologic studies clearly document that ingestion of aflatoxin $B_{1}$ is a risk factor for hepatocellular carcinoma in humans (Liu and $\mathrm{Wu}, 2010$ ). Figure (1) shows that hepatocellular cancer follows many years after the acute symptoms of aflatoxin ingestion (vomiting, abdominal pain, hemetemesis, fever, diarrhea, dizziness, and seizures) have occurred.

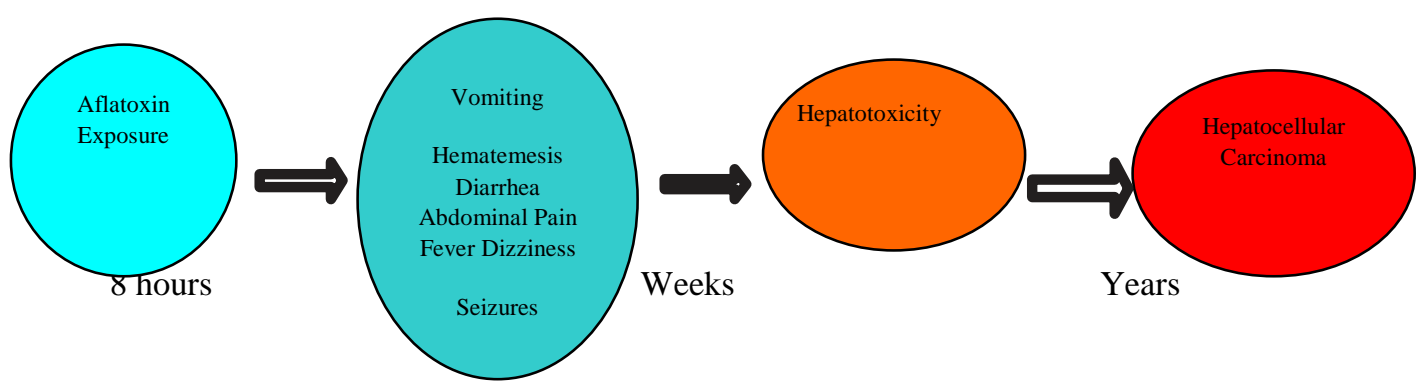

Fig 1. Time course of adverse events preceding hepatocellular carcinoma

A disease of children in Thailand with symptoms identical to that of Reye's syndrome was conjecturally associated with aflatoxicosis (Van Rensburg, 1977). This disease was characterized by vomiting, convulsions, coma, and death with cerebral oedema and fatty involvement of the liver, kidney, and heart (Bourgeois et al., 1971; Lucarelli et al., 2000). Shank (1997) found significant levels of aflatoxins (1-4 $\mu \mathrm{g} / \mathrm{kg})$ in livers of 23 Thai children who had died of Reye's syndrome. In New Zealand and Czechoslovakia, aflatoxins were found in the liver of children who died due to Reye's syndrome at autopsy. Kwashiorkor, a disease of children in Northern Africa and in undernourished populations, is usually attributed to nutritional deficiencies and may also be related to aflatoxin intake (Etzel, 2014). The liver damage induced by aflatoxins prevented the children from coping with high protein diets which are usually recommended for the treatment of Kwashiorkor (Newell, 1983; Afsah-Hejri et al., 2013).

In many species, the major target for acute and chronic toxicity due to aflatoxin exposure is the liver; however, limited information is available associating this risk with outbreaks of aflatoxin toxicity. In addition, only a few animal studies have measured aflatoxin concentrations because unbound aflatoxins remain in the blood for a very short period of time after exposure (i.e., 13-120 min) (Wong and Hsiech, 1978; Zain 2011; Alshannaq and Yu 2017). In all species and tissues tested to date, the mutagenicity, carcinogenicity and DNA-binding activity of aflatoxin $\mathrm{B}_{1}$ appear to result from its activation by cytochrome $\mathrm{P} 450$ enzymes to produce aflatoxin $\mathrm{B}_{1}-8$,9-epoxide (WHO, 2002; Josse et al. 2012 ). Microsomial mixed function oxygenase (MFOs) form $\mathrm{AFM}_{1}$, $\mathrm{AFQ}_{1}, \mathrm{AFP}_{1}$ and $\mathrm{AFB}_{1}-8,9$-oxide. Moreover, in the liver cells, $\mathrm{AFB}_{1}$ is altered by cytoplasmic reductase to form aflatoxicol (Monson et al., 2015). The 8,9-epoxide binds covalently to DNA, forming mutagenic adducts; there is a positive correlation between risk of tumor formation and levels of $\mathrm{AFB}_{1}$-DNA adducts in the liver in animal models (Josse et al.,2012). Mutations of p53 are a relevant marker in the molecular epidemiology of liver cancer, as some $20 \%$ of cases show mutations of this oncogene. Moreover, a mutation at the third base of codon 249 (a GC to TA transversion leading to a change from arginine to serine) has been described in geographical correlation studies of aflatoxin $\mathrm{B}_{1}$ intake (WHO, 2001 Josse et al., 2012). The question of whether aflatoxin is a human carcinogen or not has been difficult to resolve due to the presence of several confounding factors, including hepatitis B virus infection. However, results of epidemiological studies have shown that aflatoxin exposure is an important determinant of the variations in human liver cancer incidence (IARC, 1987; Sohn et al., 2000; Mokhles et al., 2007).

Aflatoxins are now believed to increase neonatal mortality and still-births, increase susceptibility to neonatal jaundice (Galal et al., 2006), play a role in the pathogenesis of Kwashiorkor, and increase child susceptibility to infection and malignant disease. Early and repeated exposure to aflatoxins inutero and throughout childhood might predispose the child to liver cancer later in life. Immuno- 
suppression due to aflatoxin consumption is another contributing factor (Williams et al., 2004; Gong et al., 2016).

Aflatoxins have been reported to adversely affect the outcome of lower respiratory tract infections in children (Denning et al., 1995). In one study on Gambian children, evidence of a reduced level of salivary immunoglobulin A (IgA) was found in individuals exposed to aflatoxins. No effect on antibody titer to pneumococcal and rabies vaccines was noted. In Africa, the aggressive nature of HIV infection might be partially attributed to aflatoxin-induced immune-suppression. Aflatoxins may also contribute to failure of protective immunizations (Gong et al., 2016).

\subsubsection{Ochratoxin A}

Ochratoxin (OA) is a secondary fungal metabolite of some toxigenic species of Aspergillus and Penicillium growing on cereal grains (barley, oats, rye, corn, and wheat) and other food items including coffee, milk powder, wine, and beer (Njobeh et al., 2010, Reddy and Bhoola, 2010; Cremer et al., 2011). OA is reported to be hepatotoxic, nephrotoxic, teratogenic (Abdel-Wahhab et al., 2005, 2008,2016; Costa et al., 2016), and carcinogenic to single-stomached animals (KuiperGoodman and Scott, 1989). Of greatest concern in humans is its implicated role in an irreversible and fetal kidney disease referred to as Balkan Endemic Nephropathy (BEN) (Pavlovic et al., 1999, Ringot et al., 2006; Pfohl-Leszkowicz et al., 2007). Increased incidence of renal disease is accompanied by a high risk of urinary tract tumors. In addition to OA, very low selenium levels of the population could also be a risk factor for BEN and urinary tract tumors (Miraglia et al., 1995, Miletiĉ-Medved et al., 2005; Ringot et al., 2006). OA is heat stable. El-Banna and Scott (1984) report that cooking Fava beans and polished wheat spiked with $\mathrm{OA}$ at $125 \mathrm{ng} / \mathrm{g}$ resulted in destruction of only 16-20\% and 6\% of OA, respectively. This indicates that complete destruction of OA via heat processing is not possible. Generally, no children aged 4-14 years were affected by endemic nephropathy (Akkmeteli, 1977; Breilholtz et al., 1993). Because of the long-term effects, a direct relationship is difficult to establish. Table (2) summarizes a comparison of mean dietary intake estimates for an average person calculated from occurrence and consumption data in human blood plasma.

Table 2. Comparison of estimates of mean dietary intake of OA for an average person calculated from occurrence and consumption data and from mean human blood plasma levels (SCOOP, 1996)

\begin{tabular}{lccc}
\hline Country & $\begin{array}{l}\text { Estimated daily intake } \\
\text { Average concentration } \\
\text { in blood plasma (ng/ml) } \\
\text { plasma concentration } \\
(\mathbf{n g} / \mathbf{k g ~ b w})\end{array}$ & $\begin{array}{l}\text { Estimated daily intake } \\
\text { based on occurrence data } \\
\text { and consumption data } \\
(\mathbf{n g} / \mathbf{k g ~ b w})\end{array}$ \\
\hline Denmark & 1.8 & 2.4 & 2.0 \\
France & 0.4 & 0.5 & 1.5 \\
Germany & 0.45 & 0.6 & 0.9 \\
Italy & 0.53 & 0.7 & 4.6 \\
Netherlands & & & 2.0 \\
Spain & & & 0.7 \\
Sweden & 0.18 & 0.24 & 1.5 \\
United Kingdom & & & 1.4 \\
\hline
\end{tabular}

\subsubsection{Fumonisins}


Fumonisins are structurally related mycotoxins produced by Fusarium moniliform and $F$. proliferatum which are found worldwide in corn and corn-based human foods (Rodrigues and Naehrer, 2012). Fumonisins have been associated with human esophageal cancer in regions in South Africa, Northeastern Italy, Northern China and Southeastern United States (Chu and $\mathrm{Li}$, 1994; Doko and Viscinti, 1994; Hopmans and Murphy, 1993; Rheeder et al., 1992; Sydenham et al., 1991). In these regions corn is a dietary staple, and preliminary data indicate that corn and cornbased food products from these and other regions may be significantly contaminated with fumonisins.

Thiel et al. (1992) analyzed samples of commercially available corn or corn-based products obtained from retail stores in the USA, South Africa, Egypt and Peru for fumonisin content (Table 3). Fumonisin levels detected in samples from South Africa and Peru were relatively low, while samples obtained from Egypt and the USA contained high levels of fumonisin. Analyses of cornbased children's food products collected from different areas indicated the presence of fumonisins in all samples (Table 4).

Table 3. Fumonisin levels in commercial corn products for human consumption ${ }^{\mathrm{a}}$

\begin{tabular}{lccc}
\hline Source & No. of samples & Fumonisins $\mathbf{( n g} / \mathbf{g})$ & $\mathbf{F B}_{\mathbf{2}}$ \\
\cline { 3 - 4 } & & $\mathbf{F B}_{\mathbf{1}}$ & $0-120$ \\
\hline South Africa & 68 & $0-457$ & $(21)$ \\
& & $(105)$ & $410-780$ \\
Egypt & 2 & $1780-2980$ & $(595)$ \\
& & $(2380)$ & $0-1070$ \\
USA & 29 & $0-2790$ & $(190)$ \\
& & $(711)$ & $0-135$ \\
Peru & 4 & $0-660$ & $(34)$ \\
& & $(165)$ &
\end{tabular}

${ }^{\mathrm{a}}$ Values in parentheses $=$ means.

Table 4. Total fumonisins content in corn-based children food products determined by ELISA and HPLC

\begin{tabular}{lccc}
\hline Food product & Total no. of samples & \multicolumn{2}{l}{ Fumonisin $(\mathbf{n g} / \mathbf{g}$ of food) } \\
\cline { 2 - 4 } & & Total by ELISA & Total by HPLC \\
\hline Cornflakes & 2 & ND -400 & ND \\
Corn pops cereal & 1 & 200 & ND \\
Corn starch & 1 & 500 & $<75$ \\
Infant cereal & 1 & 200 & ND \\
Infant cream corn & 1 & 200 & ND \\
\hline
\end{tabular}

$\mathrm{ND}$, none detected 


\subsubsection{Patulin}

Patulin is a mycotoxin produced by several Pencillium and Aspergillus, Byssochlamys species, with Pencillium expansum being the most commonly encountered species. This fungus is the principal cause of apple rot (Davis and Diener, 1987, Steinman et al., 1989 Boussabbeh et al., 2016). Patulin was found in commercial apple juice and apple foods for children at concentrations ranging between 10 and $170 \mathrm{ppb}$ (Prieta et al., 1994; Battilani et al., 2008). Sharma (1993) stated that the toxicity of patulin may directly affect cellular glutathione levels, mitochondrial function and integrity of the plasma membrane. Patulin also has an immunosuppressive effect and inhibits DNA synthesis (Glaser and Stopper, 2012). WHO (1996) reviewed the acute toxicity of patulin and reported that the toxic signs include agitation, convulsion, dyspnea, pulmonary congestion and edema, ulceration, hyperemia, and distension of the gastrointestinal tract. WHO recommended a maximum concentration of $50 \mathrm{ppb}$ for patulin in apple juice and apple products, whereas, some countries state a limit of $10 \mathrm{ppb}$ in baby-foods (Stoloff et al., 1991; FAO, 2005).

\subsubsection{Zearalenone}

Zearalenone is a mycotoxin produced by Fusarium species growing on corn, wheat, barley, oats, sorghum, sesame, and hay and has estrogenic and anabolic activity. When livestock was fed moldy feeds containing zearalenone, the milk and milk products produced from the animals contained estrogenic substances (Frizzell et al., 2011). Estrogenic agents can increase the plasma levels of cholesterol and triglycerides in females. An association between oral-estrogen use and myocardial infection and stroke has been described (Wallace et al., 1977). Zearalenone also causes cytogenetic effects and chromosomal aberrations (Ben Salah-Abbès et al., 2010; Ismaiel et al., 2015). The major effects of zearalenone in children are on the reproductive system, leading to hyperestrogenism and affecting reproductive organ structure and function (Kuiper-Goodman, 1991 Sherif et al., 2009; Zheng et al., 2016).

\subsubsection{Ergot}

Ergot alkaloids are produced by Claviceps purpurea and are known to be more of a problem on cereal grains (Coufal-Majewski et al., 2016). There are three main modes of action of Ergot alkaloids: peripheral, neurohormonal, and adrenergic blockage (Cordell, 1981). The most important peripheral effect is smooth-muscle contraction typified by vasoconstriction and uterotonic effects. The neurohormonal effects of ergot are observed in serotonin and adrenaline antagonism. Adrenergic blocking agents prevent the stimulation of sympathetic nerves by antagonizing the effects of other drugs such as epinephrine.

\subsubsection{Sterigmatocystin}

Sterigmatocystin ( $\mathrm{Stg})$ is a mycotoxin produced by Aspergillus genera and causes mammalian liver cancers (Adamson, 1989; Versilovskis and De Saeger, 2010). Stg was found in foods including peanuts, corn, tree nuts, cheese, milk, and meat (Diener et al., 1987; Northolt et al., 1980, Almeida et al., 2012), and has genotoxic effects in non-mammalian species (Abdel-Wahhab et al., 2005b). Stg is a major secondary metabolite of Aspergillus versicolor and A. nidulans (Sivakumar et al., 2001), is closely related to aflatoxins and is a precursor in aflatoxin biosynthesis (Barnes et al., 1994). However, the chronic or acute toxicities of Stg are considerably lower than aflatoxin (Scudamore et al., 1997). Stg is one of the predominant contaminating mycotoxins in food and grains in high-incidence malignant tumor areas in China (Huang et al., 2002). Stg is carcinogenic in mice (pulmonary adenocarcinomas) and rats (hepatocellular carcinomas) following oral administration (IARC, 1976, 1987) and is classified as an IARC Group-2B carcinogen (i.e., possibly carcinogenic to humans). The toxicity of Stg is mainly confined to the hepatic and renal tissues. However, lung tumors were also observed in newborn mice injected by a single subcutaneous dose of $5 \mathrm{mg} / \mathrm{kg}$ bw of Stg (Gujii et al., 1976). 


\subsubsection{Vomitoxin (VT)}

Vomitoxin, one of the most common mycotoxins causing vomiting among children, frequently contaminates wheat and corn. The estimated tolerable daily intake of vomitoxin is $1.5 \mu \mathrm{g} / \mathrm{kg}$ body weight and $3.0 \mu \mathrm{g} / \mathrm{kg}$ body weight for infants and adults, respectively (Kuiper-Goodman, 2004). Multiple outbreaks of vomiting illness between 1961 to 1985 in China were linked to consumption of foods made with grains contaminated with vomitoxin (Luo, 1988). In 1987, nearly 100 persons in India became ill after they consumed wheat products from which vomitoxin and other trichothecene mycotoxins were recovered (Luo et al., 1988). In 1997 and 1998, approximately 1700 school children in the United States developed vomiting, nausea, headache, and abdominal cramps after eating burritos (CDCP, 1999). Vomitoxin was identified as a contaminant in the burritos and might have caused the outbreaks, which subsided within 24 hours of onset (CDCP, 1999).

\subsection{Mycotoxin Legislation}

Limits for contaminants such as mycotoxins in foods are set in EC Regulation 466/2001 setting maximum limits for certain contaminants in foodstuffs and its amendments. Further amendments to this legislation are currently being implemented to include infant foods as described below.

EC Regulation 1425/2003 set a limit of $10 \mu \mathrm{g} / \mathrm{kg}$ of patulin for the following categories of foods:

- Apple juice or apple products prepared for young children and infants.

- Other non-cereal based baby food

This limit applies directly in the UK although provisions for the enforcement of the limit are currently being implemented into UK law. The limits apply to the product "as sold".

EC Regulation 683/2004 sets the following limits which came into force on 1 November 2004 and are set on a dry-matter basis:

- $0.5 \mu \mathrm{g} / \mathrm{kg}$ for aflatoxin $\mathrm{B}_{1}$ for baby foods and processed cereal-based foods for infants and young children, and dietary foods for special medical purposes intended specifically for infants;

- $\quad 0.025 \mu \mathrm{g} / \mathrm{kg}$ for aflatoxin $\mathrm{M}_{1}$ for infant formulae and follow-on formulae, including infant milk and follow-on milk and dietary foods for special medical purposes intended specifically for infants; and

- $0.5 \mu \mathrm{g} / \mathrm{kg}$ for ochratoxin A for baby foods and processed cereal-based foods for infants and young children, and dietary foods for special medical purposes intended specifically for infants.

\subsection{Halal strategies for the prevention of mycotoxin contamination}

The prevention of fungal contamination and mycotoxin production in agricultural commodities generally may be divided into three levels:

\subsubsection{Primary prevention}

Primary prevention is the most effective method to reduce the growth of fungi and production of mycotoxins. Several methods are recommended to prevent favourable conditions for the growth of fungi, including:

- Development of halal crop varieties resistant against fungal infection;

- Control of plant infection in the field using halal fungicides;

- Development of a suitable pre- and post-harvest schedule;

- Reducing moisture content in seeds of plants post-harvest or during storage;

- Storing commodities at low temperatures whenever possible;

- Using halal fungicides and preservatives against fungal growth during storage; 
- Control of insect infestation in stored bulk grains using approved insecticides.

\subsubsection{Secondary prevention}

This level of prevention is required when early phase fungal invasion has started in commodities. The occurrence of toxigenic fungi should be reduced or their growth stopped in order to prevent further decay and contamination with mycotoxins. Several measures are suggested as follows:

- Growth of the infested fungi should be stopped by re-drying the products;

- Contaminated seeds should be removed;

- Mycotoxin contamination should be inactivated or detoxified;

- Stored products should be protected from any favourable conditions which enhance the growth of fungi.

\subsubsection{Tertiary prevention}

If the commodities are heavily infested with toxic fungi, neither the primary nor secondary preventions are feasible. None of the primary or secondary prevention measures would be effective to stop the growth of toxic fungi and the formation of their toxins. However, several measures have to be carried out to avoid the transfer of toxic fungi and mycotoxins to food or the environment; these include detoxification or destruction of the mycotoxins to a minimal level.

\subsection{Halal decontamination strategies}

The mycotoxin-contaminated food and feed should be removed, detoxified or inactivated by chemical, physical and biological means following the Islamic view. Each treatment may have its own limitations because the treated products should be halal, safe and not affect the essential nutritive value of the product. The suggested methods for effective decontamination of some mycotoxins can be summarized as the following:

\subsubsection{Physical strategies}

Density segregation, mechanical separation, colour sorting and screening bulk grain and nut shipments significantly reduced possible mycotoxin contamination of grains. Washing using water or sodium carbonate solution reduces the presence of $\mathrm{FB}_{1}$ and ZEN in grains. Gamma irradiation is used successfully to control ochratoxin levels (Refai et al., 1996).

\subsubsection{Chemical strategies}

Several chemicals have been found to be effective (to different extents) against different mycotoxins. These chemicals fall into the following categories: acids, bases (e.g. ammonia, sodium hydroxide), oxidising reagents (e.g. hydrogen peroxide, ozone), reducing agents (e.g. bisulphite, sugars), chlorinating agents (e.g. chlorine), salts and miscellaneous reagents such as formaldehyde (Table 5).

Table 5: Chemical treatments used in the removal of mycotoxins from contaminated commodities

\begin{tabular}{|c|c|}
\hline a- Acetic acid $\left(\mathrm{C}_{2} \mathrm{H}_{5} \mathrm{OH}\right)$ & $\begin{array}{l}\text { b- Ammonia gas }\left(\mathrm{NH}_{3}\right) \text { or } \mathrm{NH}_{4} \mathrm{OH} \text { or ammonium salts, 3- } \\
5 \% \text {. }\end{array}$ \\
\hline c- Acetic acid $\left(\mathrm{C}_{2} \mathrm{H}_{5} \mathrm{OH}\right)$ & d- Calcium hydroxide $\left(\mathrm{Ca}(\mathrm{OH})_{2}\right)$. \\
\hline e- Formaldehyde. & f- Hydrogen peroxide $\left(\mathrm{H}_{2} \mathrm{O}_{2}\right)$. \\
\hline g- Methylamine $\left(\mathrm{CH}_{3}-\mathrm{NH}_{2}\right)$. & h- Ozone gas $\left(\mathrm{O}_{3}\right)$. \\
\hline i- Phosphoric acid $\left(\mathrm{H}_{3} \mathrm{PO}_{4}\right)$. & $\mathbf{j}$ - Phosphine gas $\left(\mathrm{PH}_{3}\right)$, very highly toxic! \\
\hline
\end{tabular}


k-Sodium bicarbonate $\left(\mathrm{NaHCO}_{3}\right) . \quad$ l- Sodium bisulfite $\left(\mathrm{NaHSO}_{3}\right)$.

m- Sodium bisulfite $(\mathrm{NaOH})$.

n- Sodium hypochlorite (NaOCI).

\subsubsection{Physicochemical strategies}

Phyllosilicate clay is reportedly able to chemisorb mycotoxins from aqueous solutions (Phillips et al., 2008; Abdel-Wahhab et al., 2015). The in vitro binding of aluminosilicate to $\mathrm{AFB}_{1}$ is reported to form complexes at varying strengths. Hydrated sodium calcium aluminosilicate (HSCAS) binds to $\mathrm{AFB}_{1}$ and forms a more stable complex compared to other tested compounds (Phillips et al., 2008). The HSCASs bentonite and montmorillonite were found to protect laboratory animals from toxic and teratogenic effects of aflatoxins (Abdel-Wahhab et al., 1999b, 2002b, 2015). Montmorillonite (MTT) is the active ingredient in bentonites for AF binding (Marroquín-Cardona 2009). These clays have been effectively used to reduce the negative effects of AF exposure in dairy cows (Kutz et al., 2009), goats (Smith et al., 1994), and several other animal species (Leduox et al., 1999; Phillips et al., 1999). MTT has the ability to chemisorb $\mathrm{AFB}_{1}$ and $\mathrm{FB}_{1}$ from aqueous solutions to varying degrees and form complexes of varying strengths (Zhang et al., 2010, 2011). The ability of MMT to adsorb these mycotoxins is mainly due to its high surface area. MMT is able to adsorb organic substances on external surfaces and also in the internal structures in laminar spaces via interaction with or substitution of exchange cations present in their spaces (Aly et al., 2004).

\subsubsection{Chemoprotection}

Chemoprotection against aflatoxins has been demonstrated with the use of a number of halal compounds that either increase an animal's detoxification process or prevents the production of the epoxide that leads to chromosomal damage (Kensler et al., 1993). One technical solution is drug therapy, because several compounds such as oltipraz and chlorophyll, are able to decrease the biologically effective dose of aflatoxins (Wang and Shen, 1999). Long-term therapy is expensive and may result in side effects. This would not be feasible in most developing countries. Yeast extracts and esterified glucomanoses were suggested as novel approaches to chemoprotection for aflatoxin detoxification (Kensler et al., 1993).

\subsubsection{Enterosorption}

Enterosorption is a detoxification mechanism suggested for the adsorption of clay minerals to aflatoxins to prevent its absorption in the gastrointestinal tract (Phillips et al., 2008). Adsorption agents have different efficiencies when it comes to prevention of aflatoxicosis (Phillips et al., 1993). The risk with enterosorption is non- specificity: enterosoption is feared to also act against micronutrient uptake from food (Mayura et al., 1998). However, in vitro tests of hydrated sodium calcium aluminosilicates (HSCAS) suggest that there is little adsorption of micronutrients (Chung et al., 1990). The use of HSCAS as additives in contaminated feeds is reported to be effective in preventing aflatoxin toxicity in turkeys, chickens, lambs, cattle, pigs, goats, rats, and mice (CAST, 2003; Abdel-Wahhab et al., 1998; 2002b, 2005d) and ZER (Abbès et al., 2006). Bentonite and montmorillonite were also effective in removing $\mathrm{AFB}_{1}$ and $\mathrm{FB}_{1}$ from aqueous solution (Aly et al., 2004). Recently Abdel-Wahhab et al. (2015a) reported that the modification of montmorillonite surfactants with long-chain organic cations such as Cetyltrimethyl ammoniumbromide increased hydrophobicity of the mineral surface and resulted in excellent adsorption capability of AFs, ZEN and $\mathrm{FB}_{1}$ as well as ZEN and OTA (Abdel-Wahhab et al., 2015b) in vitro and in vivo (El-Nekeety et al., 2017). 

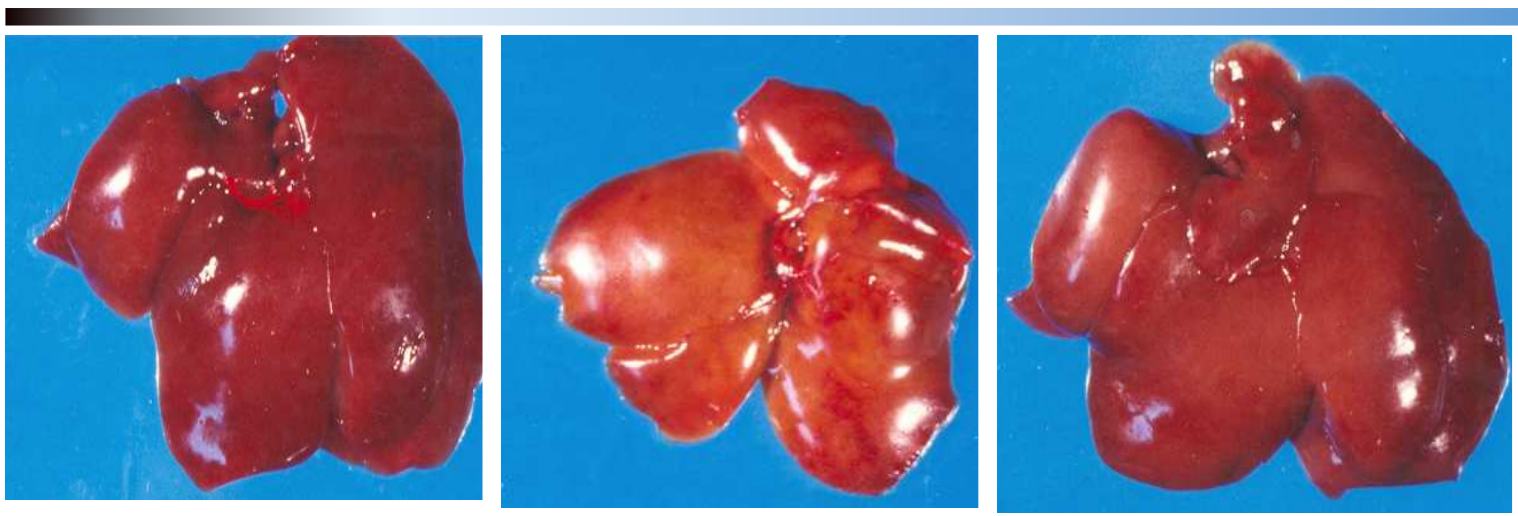

Fig. 2. Photograph showing livers of rats treated with aflatoxin alone and in combination with HSCAS or EM. Left: control (normal colour of the liver), Middle: aflatoxin treated (pale yellow liver typical of aflatoxicosis), Right: HSCAS or EM plus aflatoxin (normal comparable to the control liver) (AbdelWahhab et al., 2005c)

\subsubsection{Biological}

Biological detoxification can be defined as the enzymatic degradation or biotransformation of mycotoxins by either the whole cell or an enzyme system (Bata and Lásztity, 1999). For example, the mycotoxin $\mathrm{AFB}_{1}$ is degraded by enzymes in Flavobacterium aurantiacum (Smiley and Draughon, 2000). Other microorganisms including Rhizopus sp., Corynebacterium rubrum, Candida lipolytica, Aspergillus niger, Trichoderma viride, Mucor ambiguous, Neurospora spp., Armillariella tabescens and lactic acid bacteria have been tested in in vitro systems with varying results (Jebali et al., 2018; Karlovsky, 1999). Several microorganisms were screened for their ability to degrade OTA and convert OTA to the less toxic form, ochratoxin $\alpha$. Aspergillus niger was reportedly able to degrade ochratoxin $\alpha$ to another unknown compound. Two species of black yeast fungus (Exophiala spinifera, Rhi-nocladiella atrovirens) and a Gram-negative bacterium (Caulobacter spp.) isolated from mouldy corn kernels have been found to extensively metabolise fumonisins to $\mathrm{CO}_{2}$ in liquid media (Blackwell et al., 1999; Duvick, 2001). Several microorganisms including yeasts, fungi and bacteria are able to convert ZEN to $\alpha$ - and $\beta$-zearalenol. However, this transformation cannot be regarded as detoxification since the oestrogenic activity of the resulting metabolites is similar to that of zearalenone (Everett et al., 1987).

\subsubsection{Antioxidant strategies}

Since some mycotoxins (i.e. $\mathrm{AFB}_{1}, \mathrm{FB}_{1}$, OTA, and zearalenone) are known to cause cell membrane damage through increased lipid peroxidation (Gautier et al., 2001; Abdel-Wahhab et al., 2004a, 2005c, 2006), the protective properties of antioxidant substances against mycotoxin damage were extensively reviewed by Galvano et al. (2001). Selenium, vitamins A, C and E and their precursors showed potential antioxidant effects and acted as scavengers for superoxide anion. Moreover, several natural (provitamins, carotenoids, chlorophyll and its derivatives and phenolics) as well as synthetic compounds (butylated hydroxyanisole and butylated hydroxyl toluene) showed effective antioxidant properties.

\subsubsection{Diet and nutrients that support detoxification}

Nutrition plays a significant role in the support of detoxification. Dietary interventions intended to reduce toxicity after mycotoxins have been absorbed, are an effective detoxification strategy. Dietary interventions include intake of choline, methionine, vitamins, protein, dietary fat, antioxidants and inducers of metabolizing enzymes. This can be added to animal feeds to lower toxicity caused by mycotoxins in maize (Abdel-Wahhab et al., 1999a).

\subsubsection{Antioxidant and natural constituent defense against mycotoxins toxicity}

Feed additives such as antioxidants, sulphur-containing amino acids, vitamins, and trace elements can be useful mycotoxin detoxicants (Huwig et al., 2001; Abdel-Wahhab et al., 2004a, 2005a, 
2006; Abdel-Wahhab and Aly 2003, 2005, El-Nekeety et al, 2014). Several reports are now available that suggest that antioxidants are able to protect against chemical carcinogenesis if administered prior to/ or concomitantly with these carcinogens.

\subsection{Future strategies for mycotoxin management}

In spite of the large progress achieved in understanding the factors affecting mycotoxin production, detection and diagnosis in the past years, mycotoxins remain a food safety threat. The biggest challenges to develop and perfect strategies or technologies to guarantee food safety and ensure a healthy environment are changes in agricultural production and storage practices and food processing. This should be carried out parallel to changes in public and environmental policy

The areas of public policy and research required to ensure safe food and feed supply in the twentyfirst century are listed below:

\subsubsection{Critical Needs}

For sustained management of mycotoxins along the food chain, the following procedures are recommended:

\section{Public Policy}

1. Develop uniform standards and regulations for mycotoxin contamination.

2. Support joint international cooperation (FAO/ WHO/UNEP) to adopt standardized regulations.

3. Develop a safe food supply for local populations.

\section{Mycotoxin Detection}

1. Develop new technologies for mycotoxin analysis, including multiple-toxin analysis, and improve detection of specific mycotoxins in prepared foods.

2. Develop biomarkers for human and animal exposure to mycotoxins, including multipanel arrays that can detect exposure to multiple toxins.

\section{Human and Animal Interactions}

1. Assess mycotoxins as virulence factors.

2. Research the effect of mycotoxins as immunosuppressors.

3. Evaluate toxicological interactions of toxins with the host (activation and detoxification of mycotoxins by host metabolism).

4. Examine population variation for sensitivity to mycotoxins

5. Assess interactions between mycotoxins and drugs, diet, and nutrition.

6. Assess the role of fumonisins on humans and their involvement in esophageal cancer.

7. Assess the risks of ochratoxin exposure due to its occurrence in a variety of foods and environmental locations.

\section{Plant and Fungus Interactions}

1. Establish a better understanding of the factors affecting mycotoxin formation in the field and in storage.

2. Improve understanding of the ecology and epidemiology of mycotoxin-producing fungi.

3. Develop sound agronomic-management practices to decrease mycotoxin contamination.

4. Develop host-plant resistance to mycotoxin-producing fungi and to mycotoxin occurrence.

5. Develop models to better forecast the potential of mycotoxin contamination.

6. Research genetic regulation and biosynthesis of mycotoxins by the producing organisms.

\section{Indoor Air Quality}

1. Determine mycotoxins responsible for indoor air-quality problems.

2. Develop sound sampling protocols for assessing fungal populations. 
3. Establish limits for respiratory exposure to mycotoxins.

\section{Defence against Mycotoxins}

1- $\quad$ The first line of defence against mycotoxins is to avoid eating mouldy and rotten food.

2- $\quad$ The second line of defence is a properly functioning liver, the major organ that detoxifies harmful chemicals. Liver function can be improved by taking liver supplements such as herbs and by detoxifying the body with hyperthermia.

3- $\quad$ Plants and foods with high Brix readings will dehydrate before spoiling (getting mouldy). Therefore, high Brix readings are the third line of defence against mould and aflatoxin consumption.

4- $\quad$ The intake of antioxidant-rich foods that support the liver by helping to remove toxic chemicals from the body.

5- The intake of chlorophyll found in all green leafy vegetables.

6- $\quad$ Consumption of certain foods that are reported to provide defence against mycotoxins, such as coffee, strawberries, tea, pepper, grapes, turmeric, fava beans, garlic, cabbage, and onions as well as chemosorbent materials (Abdel-Wahhab, 2000; Abdel-Wahhab and Aly, 20031 Abdel-Wahhab et al., 1998, 1999a, 2005b, 2015b).

7- $\quad$ The use of electro-medicine that neutralizes mycotoxins in the blood.

\subsubsection{Recommendations}

1. Setup and coordinate research and monitoring programmes on different types of mycotoxins.

2. Standardize sampling, sample handling and analysis.

3. Test economic viability and acceptability of existing drying technologies.

4. Develop a field kit for analysis.

5. Improve on-farm storage facilities.

6. Improve coordination and streamlining of programs in African-Asian countries.

\section{References}

[1] Abbès, S., Ben Salah- Abbès, J., Ouanes, Z., Houas, Z., Othman, O., Bacha, H., Abdel-Wahhab, M.A., Oueslati, R. 2006. Preventive role of phyllosilicate clay on the immunological and biochemical toxicity of zearalenone in balb/c mice. Int. Immunopharm. 6, 1251-1258.

[2] Abdel-Wahhab, M.A. 2000. Antioxidant and radical scavenging effects of garlic and cabbage extracts in rats fed ochratoxin-contaminated diet. J. Egypt. Med. Assoc. 83, 1-19.

[3] Abdel-Wahhab, M.A., Abdel-Aziem, S.H., El-Nekeety, A.A. 2008. Inula crithmoides extract protect against ochratoxin A-induced oxidative stress, clastogenic and mutagenic alterations in male rats. Toxicon 52(4), 566-73.

[4] Abdel-Wahhab, M.A., Abdel-Galil, M.M., Ellithey, M.M. 2005. Melatonin counteracts oxidative stress in rats fed ochratoxin A- contaminated diet. J. Pineal Res. 38, 130-135.

[5] Abdel-Wahhab, M.A., Abdel-Galil, M.M., Hamed, N.F. 2005c. The protective effects of Hydrated Sodium Calcium Aluminosilicate and the Egyptian montmorillonite against aflatoxicosis in rats. Sc. J. Az. Med. Fac. (Girls). 26(3), 243-258.

[6] Abdel-Wahhab, M.A., Ahmed, H.H., Hagazi, M.M. 2006. Prevention of aflatoxin B -initiated $^{-}$ hepatotoxicity in rat by marine algae extracts. J. Appl. Toxicol. 26, 229-38. 
[7] Abdel-Wahhab, M.A., Aljawish, A., El-Nekeety, A.A., Abdel-Aziem, S.H., Abdel-Kader, H.A.M., Rihn, R.H., Joubert, O., 2015. Chitosan nanoparticles and quercetin modulate gene expression and prevent the genotoxicity of aflatoxin $\mathrm{B}_{1}$ in rat liver. Toxicol. Rep. 2, 737-747.

[8] Abdel-Wahhab, M.A., Aly, S.E. 2003. Antioxidants and radical scavenging properties of vegetable extracts in rats fed aflatoxin-contaminated diet. J Agric. Food Chem. 51, 2409-14.

[9] Abdel-Wahhab, M.A., Aly, S.E. 2005. Antioxidant property of Nagilia Sativa (Black cumin) and Syzygium Aromaticum (Clove) in rats during aflatoxicosis. J. Appl. Toxicol. 25, 218-223.

[10] Abdel-Wahhab, M.A., El-Denshary, E.S., El-Nekeety, A.A., Abdel-Wahhab, K.G., Hamzawy, M.A., Elyamany, M.F., Hassan, N.S., Mannaa, F.A., Shaiea, M.N.Q., Gado, R.A., Zawrah, M.F. $2015 b$. Efficacy of organo-modified nano montmorillonite to protect against the cumulative health risk of aflatoxin B1 and ochratoxin A in rats. Soft Nanosci Lett. 5, 21-35.

[11] Abdel-Wahhab, M.A., El-Nekeety, A.A., Hathout, A.S., Sabery, B.A., Ibrahim, M.I., Gado, R.A., Zawrah, M.F., Aly, S.E. 2015a. Preparation and characterization of organo-modified nano montmorillonite and evaluation of its ability to adsorb aflatoxins, fumonisins and zearalenone from aqueous solution. NanoSciTech open Lib. 1(1), 27-34.

[12] Abdel-Wahhab, M.A., Hassan, A.M., Aly, S.E., Mahrous, K.F. 2005b. Adsorption of sterigmatocystin by montmorillonite and inhibition of its genotoxicity in the Nile tilapia fish (Oreachromis nilaticus). Mut. Res. 582, 20-27.

[13] Abdel-Wahhab, M.A., Hassan, N.S., El-Kady, A.A.,Khadrawy, Y.A., El-Nekeety, A.A., Mohamed, S.R., Sharaf, H. A. and Mannaa, F.A. 2010. Red ginseng extract protects against aflatoxin $B_{1}$ and fumonisins-induced hepatic pre-cancerous lesions in rats. Food Chem. Toxicol. 48(2), 733-742.

[14] Abdel-Wahhab, M.A., Nada, S.A., Amra, H.A. 1999b. Effect of Aluminosilicates and Bentonite on aflatoxin-induced developmental toxicity in the rats. J. Appl. Toxicol.19, 199-204.

[15] Abdel-Wahhab, M.A., Nada, S.A., Arbid, M.S. 1999a. Ochratoxicosis: Prevention of developmental toxicity by L-methionine in the rats. J. Appl. Toxicol. 19, 7-12.

[16] Abdel-Wahhab, M.A., Nada, S.A., Farag, I.M., Abbas, N.F., Amra, H.A. 1998. Potential protective effect of HSCAS and Bentonite against dietary aflatoxicosis in rat: with special reference to chromosomal aberrations. Nat. Toxins 6, 211-218.

[17] Abdel-Wahhab, M.A., Salman, A.S., Ibrahim, M.I.M., El-Kady, A.A., Abdel-Aziem, S.H., Hassan, N.S., Waly, A.I., 2016. Curcumin nanoparticles loaded hydrogels protects against aflatoxin $\mathrm{B}_{1^{-}}$ induced genotoxicity in rat liver. Food Chem. Toxicol. 94, 159-71.

[18] Adamson, R.H. 1989. Introduction of hepatocellular carcinoma in nonhuman premates by chemical carcinogens. Cancer Detect. Prev. 14, 215-219.

[19] Afsah-Hejri, L., Jinap, S., Hajeb, P., Radu, S., Shakibazadeh, S.H. 2013. A Review on Mycotoxins in food and feed: Malaysia case study. Compr. Rev. Food Sci. Food Saf. 12, 629-651.

[20] Akkmeteli, M.A.1977. Epidemiological features of the mycotoxicoses, Ann. Nutr. Aliment. 31, 957976.

[21] Almeida, M.I., Almeida, N.G., Carvalho, G.A, Gonçalves, G.A., Silva, C.N., Santos, E.A., Garcia, J.C., Vargas, E.A. 2012. Co-occurrence of aflatoxins B1, B2, G1 and G2, ochratoxin A, zearalenone, deoxynivalenol, and citreoviridin in rice in Brazil. Food Addit. Contam. Part A 29, 694-703.

[22] Alshannaq, A., Yu, J. 2017. Occurrence, toxicity, and analysis of major mycotoxins in Food. Int. J. Environ. Res. Public Health.14(6),632 doi 10.3390/ijerph14060632

[23] Aly, S.E., Abdel-Galil, M.M., Abdel-Wahhab, M.A. 2004. Application of adsorbent agents technology in the removal of aflatoxin $\mathrm{B}_{1}$ and fumonisin $\mathrm{B}_{1}$ from malt extract. Food Chem. Toxicol. 42, 1825-1831.

[24] Azziz-Baumgartner, E., Lindblade, K., Gieseker, K., Rogers, H.S., Kieszak, S., Njapau, H., Schleicher, R., McCoy, L.F., Misore, A., DeCock, K., Rubin, C., Slutsker, L. 2005. Aflatoxin investigative group. case control study of an acute aflatoxicosis outbreak, Kenya. Environ. Health Perspect. 113, 1779-83.

[25] Barrett, J.R. 2000. Mycotoxins: of molds and maladies. Environ. Health Perspect; Focus, A 20-23. 
[26] Barnes, S.E., Dola, T.P., Bennett, J.W.,Bhatnagar, D. 1994. Synthesis of sterigmatocystin on a chemically defined medium by species of Aspergillus and Chaetomium. Mycopathologia 125, 173178.

[27] Baskaran, V., Narasimhamurthy, K., Nagendra, R., Lokesh, B.R. 1999. Assessment of protein quality of infant milk food formula supplemented with lactulose. Ind. J. Experim. Biolo. 37 (11), 1129-1131.

[28] Bata, A., Lásztity, R. 1999. Detoxification of mycotoxin-contaminated food and feed by microorganisms. Trends Food Sci. Technol. 10, 223-228.

[29] Battilani, P., Barbano, C., Logrieco, A. 2008. Risk assessment and safety evaluation of mycotoxins in fruits. In: Barkai-Golan, R., Paster, N. (Eds.), Mycotoxins in fruits and vegetables. Academic Press in an imprint of Elsevier, USA, pp. 1-26.

[30] Bellisle, F., Rolland-Cachera, M.F. 2000. Three consecutive (1993, 1995, 1997) surveys of food intake, nutritional attitudes and knowledge, and lifestyle in 1000 French children, aged 9-11 years. J. Human Nutr. Dietetics 13, 101-111.

[31] Ben Salah-Abbès, J., Abbès, S., Abdel-Wahhab, M.A., Oueslati, R. 2010. Immunotoxicity of zearalenone in Balb/c mice in a high subchronic dosing study counteracted by Raphanus sativus extract. Immunopharmacol. Immunotoxicol. 32(4), 628-36.

[32] Benford, D. 2001. The acceptable daily intake: A tool for ensuring food safety. International Life Sciences Institute, Brussls, Belgium.

[33] Blackwell, B.A., Gilliam, J.T., Savard, M.E., Miller, D.J., Duvick, J.P. 1999. Oxidative deamination of hydrolyzed fumonisin $\mathrm{B}_{1}$ (AP1) by cultures of Exophiala spinifera. Nat. Toxins 7, 31-38.

[34] Bourgeois, C.H., Shank, R.C., Grossman, R.A., Johnsen, D.O., Wooding, W.L., Chandavimol, P. 1971. Acute aflatoxin $B_{1}$ toxicity in the macaque and its similarities to Reye's syndrome. Lab. Invest. 24, 206-216.

[35] Boussabbeh, M., Ben Salem, I., Belguesmi, F., Neffati, F., Najar, M.F., Abid-Essefi, S., Bacha, H. 2016. Crocin protects the liver and kidney from patulin-induced apoptosis in vivo. Environ Sci Pollut Res Int 23(10), 9799-808.

[36] Breilholtz, E.A., Olsen, M., Oskarsson, A., Palminger, I., Hult, K. 1993. Ochratoxin A in cow's milk and human milk with corresponding human blood samples. JAOAC 76, 842-846.

[37] Bullerman, L.B. 2002. Processing Effects on Mycotoxins: Introduction. In DeVries, J W, Trucksess, M W; Jackson, L S (eds). Mycotoxins and Food Safety. Book Series: Advances In Experimental Medicine and Biology: Volume 504, Kluwer Academic/ Plenum Publishers. NY.

[38] CAST. 2003. Mycotoxins: risks in plant, animal, and human systems. task force report No. 139, Ames, Iowa, United States.

[39] CDCP. 1999. Centers for Disease Control and Prevention. Outbreaks of gastrointestinal illness of unknown etiology associated with eating burritos.United States, October 1997-October 1998. MMWR Morb Mortal Wkly Rep; 48, 210-213.

[40] CDCP. 2000. Centers for disease control and prevention. Update: pulmonary hemorrhage/hemosiderosis among infants. Cleveland, Ohio, 1993-1999. Morb. Mortal. Wkly Rep; $49,180-184$.

[41] CDCP. 2004. Centers for disease control and prevention. Outbreak of aflatoxin poisoning eastern and central provinces, Kenya, Morb Mortal Wkly Rep (MMWR) 53-34, 790-793.

[42] Chu, F.S., Li, G.Y. 1994. Simultaneous occurrence of fumonisin $B_{1}$ and other mycotoxins in moldy corn collected from the People's Repuplic of China in regions with high incidence of esophageal cancer. Appl. Environ. Microbiol. 60, 847-852.

[43] Chung, T.K., Baker, D.H., Erdman, J.W.J. 1990. Hydrated sodium calcium aluminosilicate: effects on zinc, manganese, vitamin A and riboflavin utilization. Poult. Sci. 69, 1364 -70.

[44] Cordell, G.A. 1981. Ergot alkaloids. In introduction to alkaloids: a biogenetic approach, John Wiley and Sons, New York, pp 622-654. 
[45] Costa, J.Gm, Saraiva, N., Guerreirom, P.S., Louro, H., Silva, M.J., Miranda, J.P., Oliveira, N.G. 2016. Ochratoxin A-induced cytotoxicity, genotoxicity and reactive oxygen species in kidney cells: An integrative approach of complementary endpoints. Food Chem.Toxicol 87, 65-76.

[46] Coufal-Majewski, S., Stanford, K., McAllister, T., Blakley, B., McKinnon, J., Chaves, A.V. Wang Y. 2016. Impacts of cereal ergot in food animal production. Front Vet Sci 3,15.

[47] Cremer, B., Soja, A., Sauer, J.A., Damm, M. 2011. Pro- inflammatory effects of Ochratoxin A on nasal epithelial cells. Eur. Arch. Otorhino-laryngol. 269, 1155-161.

[48] Davis, N.D., Diener, U.L. 1987. Mycotoxins, In Beuchat, L.R. (ed): Food and Beverage Mycology. Van Nostrand Reinhold, New York, Pp 517-524.

[49] Denning, D.W., Quiepo, S.C., Altman, D.G., Makarananda, K., Neal, G.E., Camallere, E.L., Morgan, M.R., Tupasi, T.E. 1995. Aflatoxin and outcome from acute lower respiratory infection in children in The Philippines. Ann. Trop. Paediatr. 15, 209-216.

[50] Diener, U.F., Cole, R.J., Sabders, T.H., Payne, G.A., Lee, L.S., Klich, M.A. 1987. Epidemiology of aflatoxin formation by Aspergillus flavus. Annu. Rev. Phytopatholo. 25, 249-270.

[51] Doko, M.B., Visconti, A. 1994. Occurrence of fumonisin $B_{1}$ and $B_{2}$ in corn and corn-based human foodstuff in Italy. Food Addit. Contam. 11, 433-439.

[52] Duvick, J. 2001. Prospects for reducing fumonisin contamination of corn through genetic modification. Environ. Health Perspect. 109, 337-342.

[53] El-Banna, A.A., Scott, P.M. 1984. Fate of mycotoxins during processing of foodstuffs: III. Ochratoxin A during cooking of Faba Beans (Vicia faba) and polished wheat. J. Food Protect. 47, 189-192.

[54] El-Nekeety, A.A., Abd El-Aziem, S.H., Hassan, A.M., Aly, S.E., Abdel-Wahhab, M.A. 2014. Quercetin inhibits the cytotoxicity and oxidative stress in liver of rats fed aflatoxin-contaminated diet. Toxicol. Rep. 1, 319-329.

[55] El-Nekeety, A.A., Salman, A.S., Hathout, A.S., Sabry, B.A., Abdel-Aziem, S.H., Hassan, N.S., Abdel-Wahhab, M.A., 2017. Evaluation of the bioactive extract of actinomyces isolated from the Egyptian environment against aflatoxin $\mathrm{B}_{1}$-induce cytotoxicity, genotoxicity and oxidative stress in the liver of rats. Food Chem. Toxicol. 105, 241-255.

[56] Etzel, R.A. 2014. Reducing malnutrition: time to consider potential links between stunting and mycotoxin exposure? Pediatrics 134(4) doi: 10.1542/peds.2014-0827

[57] Everett, D.J., Perry, C.J., Scott, K.A., Martin, B.W., Terry, M.K. 1987. Estrogenic potencies of resorcylic acid lactones and 17 beta-estradiol in female rats. J. Toxicol. Environ. Health 20, 435-443.

[58] FAO. 1996. Basic facts on the world cereal situation. Food Outlook, 5/6. Rome.

[59] FAO. 2001. Manual of the application of HACCP system in Mycotoxin prevention and control. FAO Food and Nutrition paper No. 73, FAO, Rome.

[60] FAO. 2005. The state of food insecurity in the world 2005 eradicating world hunger -key to achieving the Millennium Development Goals. The Food and Agriculture Organization of the United Nations, Rome.

[61] Forrest, C.B., Riley, A.W. 2004. Childhood origins of adult health: a basis for life-course health policy. Health Aff (Millwood) 23, 155-164.

[62] Frizzell, C., Ndossib, D., Verhaegenb, S., Dahlb, E., Eriksend, G., Sørliee, M., Ropstadb, E., Mullerf, M., Elliotta, C.T., Connolly, L. 2011. Endocrine disrupting effects of zearalenone, alpha- and beta-zearalenol at the level of nuclear receptor binding and steroidogenesis.Toxicol. Lett. 206(2), 210217.

[63] Fung, F., Clark, R. 2004. Health effects of mycotoxins: a toxicological overview. J Toxicol. 42, 217234.

[64] Galal, N., Gamal El-Din, R.M., Arafa, A., Mohamad, I.M., Abdel-Wahhab, M.A. 2006. Aflatoxin levels in Egyptian neonates with unexplained neonatal jaundice: Morbidity and correlation to maternal assays in breast milk. The Egypt. J. Neonatol. 7(3), 161-169. 
[65] Galal-Gorchev H. 1993. Dietary intake, levels in food and estimated intake of lead, cadmium, and mercury. Food Addit. Contam. 10(1), 115-128.

[66] Galvano, F., Piva, A., Ritieni, A., Galvano, G. 2001. Dietary strategies to counteract the effects of mycotoxins: a review. J. Food Protec. 64, 120-131.

[67] Gautier, J.C., Holzhaeuser, D., Markovic, J., Gremaud, E., Schilter, B., Turesky, R.J. 2001. Oxidative damage and stress response from ochratoxin A exposure in rats. Free Radic. Biol. Med. 30, 10891098.

[68] Gelderblom, W.C., Marasas, W.F. 2012. Controversies in fumonisin mycotoxicology and risk assessment. Hum. Exper Toxicol 31(3), 215-235.

[69] Glaser, N., Stopper, H. 2012. Patulin: mechanism of genotoxicity. Food Chem. Toxicol. 50, 17961801

[70] Gong, Y., Watson, S., Routledge, M.N. 2016. Aflatoxin exposure and associated human health effects, a review of epidemiological studies. Food Safety 4(1), 14-27.

[71] Gujii, K., Kurato, H., Odashima, S., Hatsuda, Y. 1976. Tumor induction by a single subcutaneus injection of sterigmatocystin in new born mice. Cancer Res. 36, 1615-1618.

[72] Gursky, S. 2000. Allocare in a nocturnal primate: Data on the spectral tarsier, Tarsius spectrum. FoliaPrimatologica. 71 (1-2), 39-54.

[73] Heussner, A.H., Bingle, L.E. 2015. Comparative ochratoxin toxicity: A Review of the available data. Toxins (Basel) 7(10), 4253-4282.

[74] Hisako, S., Yasushi, W., Hiroko, F., Tomoya, Y., Hajime, A., Hiroshi, K., Shiro, S., Yoshiko, S. 2013. Estimated dietary exposure to mycotoxins after taking into account the cooking of staple foods in Japan. Toxins, 5, 1032-1042.

[75] Hopmans, E.C., Murphy, P.A. 1993. Detection of fumonisin $B_{1}, B_{2}$ and $B_{3}$ and hydrolyzed fumonisin $\mathrm{B}_{1}$ in corn-containing foods. J. Agric. Food Chem. 41, 1655-1658.

[76] Huang, X., Zhang, X., Yan, X., Yin, G. 2002. Effects of sterigmatocystin on interleukin-Z secretion of human peripheral blood manonuclear cells in vitro. Wei Sheng Yan 31 (2), 112-114.

[77] Huwig, A., Freimund, S., Kappeli, O., Dutler, H. 2001. Mycotoxin detoxication of animal feed by different adsorbents. Toxicol. Lett. 122, 179-188.

[78] IARC. 1993a. Aflatoxins. In IRAC Monographs on the evaluation of Carcinogenic Risks to Humans, vol.56, IRAC, Lyon, France, Pp243-395.

[79] IARC. 1993b. Ochratoxin A. In: IRAC Monographs on the evaluation of Carcinogenic Risks to Humans, vol.56.IRAC, Lyon, France, pp 489-521.

[80] IARC. 1993c. Toxins derived from Fusarium monilliforme. Fumonisin $\mathrm{B}_{1}$ and $\mathrm{B}_{2}$ and Fusarin C. In: IRAC Monographs on the evaluation of Carcinogenic Risks to Humans, vol.56, IRAC, Lyon, France, pp445-466.

[81] IARC. 1993e. IARC Monographs on the evaluation of carcinogenic risks of chemicals of humans. Some naturally occurring substances: Some food items and constituents, Heterocyclic aromatic amins and mycotoxins, Lyon, France: IRAC, vol 56.

[82] IARC. 2015. Mycotoxin control in low- and middle income countries (pp. 31-42). Lyon, France: International Agency for Research on Cancer (WHO). Report No. 9.

[83] IARC.1993d. Toxins derived from Fusarium sporotrichioides: T-2 toxin. In IRAC Monographs on the evaluation of Carcinogenic Risks to Humans, vol.56, IRAC, Lyon, France, pp467-488.

[84] Ismaiel, A.A.M., El-Denshary, E.S., El-Nekeety, A.A., Al-Yamani, A.F., Gad, S.A., Hassan, N.S., Abdel-Wahhab, M.A. 2015. Ameliorative effects of curcumin nanoparticles on hepatotoxicity induced by zearalenone mycotoxin. Global J. Pharmacol. 9 (3), 234-245

[85] Jarvis, B.B. 2002. Chemistry and toxicology of molds isolated from water damaged buildings. In deVries, J.W. Trucksess, M.W. and Jackson, L.S. (eds.), Mycotoxins and food safety. Kluwer Academic/ Plenum Publications, New York, N.Y. pp. 43-52. 
[86] Johnston, C.S., Monte, W.C. 2000. Infant formula ingestion is associated with the development of diabetes in the BB/Wor rat. Life-Sci. 66 (16), 1501-1507.

[87] Jonsyn FE, Maxwell SM, Hendrickse RG. (1999). Ochratoxin A and aflatoxins in breast milk samples from Sierra Leone. Mycopathologia 131, 121-126.

[88] Josse, R., Dumont, J., Fautre, A., Robin, M., Guillouzo, A. 2012. Identification of early target genes of aflatoxin $B_{1}$ in human hepatocytes, inter-individual variability and comparison with other genotoxic compounds. Toxicol. Appl. Pharmacol. 258,176-187.

[89] Karlovsky, P. 1999. Biological detoxification of fungal toxins and its use in plant breeding, feed and food production. Nat. Toxins 7, 1-23.

[90] Kaushik G. 2015. Effect of processing on mycotoxin content in grains. Crit. Rev. Food Sci. Nutr.55,1672-1683. doi: 10.1080/10408398.2012.701254.

[91] Kensler, T.W., Davis, E.F., Bolton, M.G. 1993. Strategies for chemoprotection against aflatoxininduced liver cancer. In: Eaton D, Groopman JD, eds. The toxicology of aflatoxins: human health, veterinary, and agricultural significance. London: Academic Press, pp 281-306.

[92] Kuiper-Goodman, T. 1991. Risk assessment to humans of mycotoxins in animal-derived food products. Vet. Hum. Toxicol. 33, 325-333.

[93] Kuiper-Goodman, T. 2004. Risk assessment and risk management of mycotoxins in food. In Mogan, $\mathrm{N}$ and Olsen (eds): Mycotoxins in Food, Detection and control. CRC Press New York, Wood head Publishing Limited, Cambridge, England. Pp 3-31.

[94] Kuiper-Goodman, T., Scott, P.M. 1989. Risk assessment of the mycotoxin ochratoxin A. Biomed. Environ. Sci. 2, 179-248.

[95] Kumar, P., Mahato, D.K., Kamle, M., Mohanta, T.K. and Kang, S.G. 2017. Aflatoxins: A global concern for food safety, human health and their management. Front Microbiol. 7, 2170-2177.

[96] Liu, Y., Wu, F. 2010. Global burden of aflatoxin-induced hepatocellular carcinoma: a risk assessment. Environ. Health Perspect. 118(6), 818-24.

[97] Lucarelli, S., Corrado, G., Pelliccia, A., D'Ambrini, G., Cavaliere, M., Barbato, M., Lendvai, D., Frediani, T. 2000. Cyclic vomiting syndrome and food allergy intolerance in seven children: A possible association. Eur. J. Pediatrics.159 (5), 360-363.

[98] Luo, X.Y. 1988. Outbreaks of moldy cereal poisonings in China. In: Toxicology forum and the Chinese Academy of Preventive Medicine. Issues in Food Safety. Washington, DC: Toxicology Forum; p. 56-63.

[99] Luongo, D., Russo, R., Balestrieri, A., Marzocco, S., Bergamo, P., Severino, L., 2014. In vitro study of $\mathrm{AFB}_{1}$ and $\mathrm{AFM}_{1}$ effects on human lymphoblastoid Jurkat T-cell model. J. Immunotoxicol. 11, 353358.

[100] Magnuson, B., Munro, I., Abbot, P., Baldwin, N., Lopez-Garcia, R., Ly, K., McGirr, L., Roberts, A., Socolovsky, S. 2013. Review of the regulation and safety assessment of food substances in various countries and jurisdictions. Food Addit. Contam. Part A Chem. Anal. Control Expo. Risk Assess. 30(7), 1147-1220.

[101] Marin, S., Ramos, A.J., Cano-Sancho, G., Sanchis,V. 2013. Mycotoxins: Occurrence, toxicology, and exposure assessment. Food Chem. Toxicol. 60, 218-237.

[102] Mayura, K., Abdel-Wahhab, M.A., McKenzie, K.S., Sarr, A.B., Edwards, J.F., Naguib, K., Phillips, T.D. 1998. Prevention of maternal and developmental toxicity in rats via dietary inclusion of common aflatoxin sorbents: Potential for hidden risks. Toxicol. Sci 41, 175-182.

[103] Miletiĉ-Medved, M., Domijan, A.-M., Peraica, M., 2005. Recent data on endemic nephropathy and related urothelial tumors in Croatia. Wiener Klinische Wochenschrift, 117, 604-609.

[104] Milićević, D., Nastasijevic, I., Petrovic, Z. 2016. Mycotoxin in the food supply chain-implications for public health program. J, Environ. Sci Health Part C, Environ. Carcino. Ecotoxicol Rev. 34(4):293319. 
[105] Miraglia, M., deDominicis, A., Brera, C., Corneli, S., Cava, E., Menghetti, E., Miraglia, E. 1995. Ochratoxin A level in human milk and related food samples, an exposure assessment. Nat. Toxins $3(6), 436-444$.

[106] Mokhles, M., Abdel-Wahhab, M.A., Tawfik, M., Ezzat, W., Gamil, K., Mohamed, M.I. 2007. Detection of aflatoxin among hepatocellular carcinoma patients in Egypt. Pak. J. Biol. Sci. 10(9), $1422-1429$.

[107] Monson, M.S., Roger, A., Coulombe, R.A., Reed, K.M. 2015. Aflatoxicosis: Lessons from Toxicity and Responses to Aflatoxin $B_{1}$ in Poultry. Agric 5, 742-777; doi:10.3390/agriculture5030742

[108] NAS. 1993. Pesticides in the diets of infants and children, Washington, DC, National Academy Press.

[109] NAS. 2004. Children's Health, the nation's wealth: assessing and improving child health. Washington, DC: National Academy Press.

[110] Newell, J. 1983. Treatment for starvation may kill. New Scientist 99, 471-475.

[111] Njobeh, P.B. Dutton, M.F., Makun, H.A., 2010. Mycotoxins and health: Significance, Prevention and control. In smart Biomolecules in Medicine Research Singnpost/Transworld Research Network (Ed). VBRI Press, India 132-177.

[112] Northolt, M.D., Van Egmond, H.P., Soentoro, P., Deijll, E. 1980. Fungi growth and the presence of sterigmatocystin in hard cheese. J. Assoc. Off. Anal. Chem. 63, 115-119.

[113] Oliveira, C.A.F., Germano, P.M.L., Bird, C., Pinto, C.A. 1997. Immunochmecal assessment of aflatoxin $\mathrm{M}_{1}$ in milk powder consumed by infants in Sao Paulo, Brazil. Food Addit. Contam. 14 (1), $7-10$.

[114] Ostry, V., Mali, F., Toman, J., Grosse, Y. 2017. Mycotoxins as human carcinogens-the IARC Monographs classification. Mycotoxin Res. 33(1), 65-73.

[115] Pavlovic, M., Plestina, M., Krogh, P. 1999. Ochratoxin A contamination of food stuffs in an area with Balkan (endemic) nephropathy. Acta Path. Microbiol. Scand. 87, 243-246.

[116] Pereira, V.L., Fernandes, J.O., Cunha, S.C. 2014. Mycotoxins in cereals and related foodstuffs: A review on occurrence and recent methods of analysis. Trends Food Sci. Technol. 36, 96-136.

[117] Pfohl-Leszkowicz, R.A., Manderville, A. 2007. Ochratoxin A: an overview on toxicity and carcinogenicity in animals and humans. Mol. Nutr. Food Res. 51 (1), 61-99.

[118] Phillips, T.D., Afriyie-Gyawu, E., Williams, J., Huebner, H., Ankrah, N.A., Ofori-Adjei, D., Jolly, P., Johnson, N., Taylor, J., Marroquin-Cardona, A., Xu, L., Tang, L., Wang, J.S. 2008. Reducing human exposure to aflatoxin through the use of clay: A review. Food Addit. Contam. Part A. 25, 134-145.

[119] Phillips, T.D., Clement, B.A., Park, D.L. 1993. Approaches to reduction of aflatoxin in foods and feeds. In: Eaton DL, Groopman JD, eds. The toxicology of aflatoxins: human health, veterinary, and agricultural significance. London: Academic Press, pp 383- 406.

[120] Phillips, T.D., Kubena, L.F., Harvey, R.B., Taylor, D.R., Heidelbaugh, N.D. 1988. Hydrated sodium calcium aluminosilicate: high affinity sorbent for aflatoxin. Poult. Sci 67, 243-247.

[121] Polychronaki, N., Hannu, M., Paul, T.C., Yunyun, G., Amra, H., Abdel-Wahhab, M.A., El-Nezami, H. 2006. Determinants of $\mathrm{AFM}_{1}$ in breast milk of Egyptian mothers. Food Add. Cont. 23 (7), 700-708.

[122] Prandini, A., Tansini, G., Sigolo, S., Filippi, L., Laporta, M., Piva, G. 2009. On the occurrence of aflatoxin M1 in milk and dairy products. Food Chem. Toxicol. 7, 984-991.

[123] Prieta, J., Moreno, M.A., Diaz, S., Suarez, G., Dominguez, L. 1994. Survey of patulin in apple juice and children's apple foos by the diphase dialysis membrane procedure. J. Agric. Food Chem. 42, 1701-1703.

[124] Reddy, L., Bhoola, K., 2010. Ochratoxin - Food contaminants: impact on human health. Toxins 2,771779.

[125] Refai, M.K., Aziz, N.H., El-Far, F., Hassan, A.A. 1996. Detection of ochratoxin produced by Aspergillus ochraceus in feedstuffs and its control by ã radiation. Appl. Radiat. Isot. 47, 617-621. 
[126] Rheeder, J.P., Marasas, W.F.O., Thiel, P.G., Sydenham, E.W., Shephard, G.S., Schalkwyk, D.J. 1992. Fusarium moniliforme and fuminonisins in relation to human esophageal cancer in Transkei. Phytopathol. 82, 353-357.

[127] Ringot, D., Chango, A. 2010. Risk assessment of ochratoxin A (OTA). In:Rai M, Varma A, eds. Mycotoxins in Food, Feed and Bioweapons. Heidelberg, Germany: Springer-Verlag, 307328.

[128] Ringot, D., Chango, A., Schneider, Y.J., Larondelle, Y., 2006. Toxicokinetics and toxicodynamics of ochratoxin A, an update. Chem. Biol. Interact. 159, 18-46.

[129] Rodrigues, I., Naehrer, K. 2012. A three-year survey on the worldwide occurrence of mycotoxins in feedstuffs and feed. Toxins 4,663-675.

[130] Scheuplein R, Charnley G, Dourson M. 2002. Differential sensitivity of children and adults to chemical toxicity. I: Biological basis. Regul. Toxicol. Pharmacol. 35, 429-447.

[131] SCOOP. 2002. Reports on tasks for scientific cooperation Report of experts participating in Task 3.2.7. Assessment of dietary intake of Ochratoxin A by the population of EU Member States Directorate-General Health and Consumer Protection

[132] Scudamore, K.A., Hetmanski, M.T., Clarke, P.A., Barnes, K.A., Startin, J.R. 1997. Analytical methods for determination of sterigmatocystin in cheese, bread and corn products using HPLC with atmospheric pressure ioniaztion mass spectrometric detection. Food Addit. Contam. 13, 343-358.

[133] Shank, R.C. 1997. Environmental cancer. Pp291-318. In H. F. Kraybill and M. A. Mehlman (Eds). John Wiley and Sons, Ltd., New York.

[134] Sharma, R.P. 1993. Immunotoxicity of mycotoxins. J. Dairy Sci. 76, 892-897.

[135] Sherif, S.O., Salama, E.E., \& Abdel-Wahhab, M.A. (2009). Mycotoxins and child health: The need for health risk assessment. Int J. Hyg Environ. Health 212 (4), 347-368.

[136] Sivakumar, V., Thanislass, J., Niranjlai, S., Devaraj, H. 2001. Lipid peroxidation as a possible secondary mechanism of sterigmatocystin toxicity, Hum. Exp. Toxicol. 20 (8), 398-403.

[137] Skaug, M.A. 1999. Analysis of Norwegian milk and infant formulas for ochratoxin A. Food Add. Contam. 16 (2), 75-78.

[138] Skaug, M.A., Stormey, F.C., Saugstad, O.D. 1998. Ochratoxin A: a naturally occurring mycotoxin found in human milk samples from Norway. Acta Paediatr. 87(12), 1275-1278.

[139] Skipper, P.L., Tannenbaum, S.R., 1990. Protein adducts in the molecular dosimetry of chemical carcinogens. Carcinogenesis 11, 507-518.

[140] Smiley, R.D., Draughon, F.A. 2000. Preliminary evidence that degradation of aflatoxin $B_{1}$ by Flavobacterium aurantiacum is enzymatic. J. Food Prot. 63, 415-418.

[141] Sohn, Y.M., Rho. H.O., Park, M.S., Park, J.H., Choi, B.Y., Ki, M., Jang, W.I. 2000. The changing epidemiology of hepatitis A in children and the consideration of active immunization in Korea. Yonsei Med. J. 41 (1), 34-39.

[142] Steinman, R., Seigle-Murandi, F., Sage, L., Krivobok, S. 1989. Production of patulin by Micromycetes. Mycopathologia 105, 129-133.

[143] Stoloff, L., van Egmond, H.P., Park, D.L. 1991. Rationales for the establishment of limits and regulations for mycotoxins. Food Add. Contam. 8, 213-222.

[144] Sun, X.D., Su, P., Shan, H. 2017. Mycotoxin contamination of rice in China. J. Food Sci. 82(3), 573584.

[145] Sydenham, E.W., Shephard, G.S., Thiel, P.G., Marasas, W.F.O., Stockenstrom, S. 1991. Fumonisin concentration of commercial corn-based human foodstuffs. J. Agric. Food Chem. 25, 767-771.

[146] Tamburlini, G., Von Ehrenstein, O.S., Bertollini, R. 2002. Children's health and environment: a review of evidence. a joint report from the European environment Agency and the WHO Regional Office for Europe. Luxembourg: Office for Official Publications of the European Communities. 
[147] Thiel, P.G., Marasas, W.F.O., Sydenham, E.W., Shephard, G.S., Gelderbolom, W.C.A. 1992. The implication of naturally occurring levels of fumonisins in corn for human and animal health. Mycopathologia 117, 3-9.

[148] Thompson, K.M. 2004. Changes in children's exposure as a function of age and the relevance of age definitions for exposure and health risk assessment. Medscape General Med. 6, 2-6.

[149] Van Rensburg, S.J.1977. Role of epidemiology in the elucidation of mycotoxin health risks. Pp 699712. In J. V. Rodricks, C. W. Hesseltine, and M. A. Mehlman (Eds). Mycotoxins in human and animal health. Pathotox Publishers, Inc., Park Forest South, Illinois.

[150] Versilovskis, A., De Saeger, S. 2010. Sterigmatocystin: Occurrence in foodstuffs and analytical methods-An overview. Mol. Nutr. Food Res. 54(1),136-47. doi: 10.1002/ mnfr.200900345.

[151] Wallace RB, Hoover L, Sandler D, Rifkind BM, Tyroler HA. (1977). Altered plasma-lipids associated with oral contraceptive or oestrogen consumption: The research clinic program, Lancet 2, 11-14.

[152] Wang, J.S., Shen, X., He, X. 1999. Protective alterations in phase 1 and 2 metabolism of aflatoxin $B_{1}$ by oltipraz in residents of Qidong, People's Republic of China. J. Natl. Cancer Inst. 91, 347-54.

[153] Weidenborner, M. 2001. Encyclopedia of food mycotoxins. Springer; London.

[154] WHO. 1996. Joint FAO/WHO Expert Committee on Food Additives (JECFA). Toxicological evaluation of certain food additives and contaminants in foods. Patulin, First draft prepared by M. F. A. Wouters and G. J. A. Speijers. WHO Food Additives Series No. 35. V. pp 377-402.

[155] WHO. 1999. Principles for the assessment of risk to human health from exposure to chemicals. Environmental Health Criteria 210. WHO, Geneva.

[156] WHO. 2001. Biomarkers in risk assessment: validity and validation, Environmental health criteria.

[157] WHO. 2002. Evaluation of certain mycotoxins in food. Fifty-sixth report of the Joint FAO/WHO Expert Committee on Food Additives, WHO, Technical Report Series 906, WHO, Geneva.

[158] WHO. 2006. Principles for evaluating health risks in children associated with exposure to chemicals (Environmental health criteria.

[159] WHO.1986. Principles for evaluating health risks from chemicals during infancy and early childhood; the need for a special approach, IPCS, Environmental Health Criteria 59. WHO, Geneva.

[160] Williams, J.H., Phillips, T.D., Jolly, P.E., Stiles, J.K., Jolly, C.M., Aggarwal, D. 2004. Human aflatoxicosis in developing countries: a review of toxicology, exposure, potential health consequences, and interventions. Am. J. Clin Nutr. 80, 1106-1122.

[161] Wogan, G.N. 1999. Aflatoxins as a human carcinogen. Hepatology 3, 573-575.

[162] Wong, J.J., Hsieh, D.P.H. 1978. Mutagenicity of aflatoxins related to their metabolism and carcinogenic potential. Proc. Natl. Acad. Sci. USA 73, 2241-2244.

[163] Worm, M., Ehlers, I., Sterry, W., Zuberbier, T. 2000. Clinical relevance of food additives in adult patients with atopic dermatitis. Clin. Exp. Allergy. 30 (3), 407-414.

[164] Zain, M. E. 2011. Impact of mycotoxins on humans and animals. J Saudi Chem. Soc.15( 2),129-144.

[165] Zheng, W., Pan, S., Wang, G., Wang, Y.J., Liu, Q., Gu, J., Yuan, Y., Liu, X.Z., Liu, Z.P., Bian, J.C. 2016. Zearalenone impairs the male reproductive system functions via inducing structural and functional alterations of sertoli cells. Environ. Toxicol. Pharmacol. 42, 146-55. 